\title{
La biopolítica del franquismo desarrollista: hacia una nueva forma de gobernar (1959-1975)
}

\author{
(The bio-politics of the developmentalist \\ Francoism: toward a new form of government \\ (1959-1975))
}

Salvador CAYUELA SÁNCHEZ

Recibido: 30 de septiembre de 2012

Aceptado: 30 de enero de 2013

\section{Resumen}

En el presente artículo pretendo mostrar las notas características de la biopolítica desplegada en España durante el llamado franquismo desarrollista o tardofranquismo, en el período comprendido entre 1959 y 1975. Para ello, distinguiré tres ámbitos de estudio -el económico, el socio-sanitario y el ideológico-, analizando brevemente y para cada uno de ellos los distintos dispositivos biopolíticos -disciplinarios y reguladores- más característicos. A su vez, el análisis de dichos dispositivos me permitirá trazar las notas características de aquello que podríamos llamar la gubernamentalidad tardofranquista, entendida como las formas de conducción de conductas desplegadas por el régimen en la etapa analizada. Finalmente, todo ello hará posible aportar una nueva interpretación sobre la caída del régimen franquista, señalar la efectividad o no de sus dispositivos biopolíticos, y anunciar el nacimiento de una nueva forma de gubernamentalidad ya en la España de la democracia.

Palabras clave: biopolítica, franquismo desarrollista, gubernamentalidad, subjetividad, dispositivos biopolíticos.
Abstract
In this article I want to show the characteristic elements of the bio-politics in the developmentalist Francoism, from 1959 to 1975. For this, I will distinguish three fields of study - economic, health and the ideological - and I will analyze the most 
characteristic - disciplinaries and regulatories - bio-political devices for each of them. At the same time, the analysis of these devices will allow me to show the most distinctive elements of the governmentality of the last Francoism, understanding this concept as "conduct of conducts" tried out by the Franco's regime in this period. Finally, all of this will allow me to provide a new interpretation about the end of the Franco's regime, indicating the effectiveness of its bio-political devices, and announce the birth of a new governmentality in Spain with the democracy arrival.

Keywords: bio-political, developmentalist Francoism, gouvernmentality, subjectivity, bio-political devices.

El régimen franquista nació en el marco de una excepcionalidad bélica, efecto de los aconteceres de un enfrentamiento armado y civil. La importancia que en un contexto tal debieron adquirir la violencia y el miedo generalizado para la constitución del nuevo sistema político resulta por ello absolutamente innegable1. En este sentido, la extensión de un vasto sistema policial en el que la delación y la alteración jurídica eran la norma, debió jugar un papel indudablemente determinante en la institucionalización y sostenimiento del nuevo sistema. No obstante, y al margen de la tragedia humana, social y cultural que ello supuso, la toma violenta del poder por parte del régimen franquista no puede ser entendida, en efecto, como un momento histórico excepcional. Bien al contrario, son muchos los pensadores que han llamado la atención sobre este hecho mil veces constatado en la historia de la Humanidad, desde Nicolás Maquiavelo ${ }^{2}$ hasta Karl Marx ${ }^{3}$, desde Friedrich Nietzsche ${ }^{4}$ hasta Walter Benjamin ${ }^{5}$. Ahora bien, todos ellos han señalado al tiempo la necesidad imperiosa de tales regímenes de activar o reactualizar todo un conjunto de dispositivos destinados -como la propia Ley- a dotar a sus instituciones de la legitimidad necesaria para permitir su continuidad en el tiempo, quedando así ocultos sus oscuros orígenes.

Sin pretender negar el inmenso poder estabilizador que la violencia generalizada supuso para el Nuevo Estado franquista en su mismo momento fundacional, éste no habría sobrevivido en efecto sin la extensión por todo el cuerpo social de ciertos mecanismos destinados, precisamente, al sostenimiento y legitimación interior de la dictadura. Efectivamente, el régimen franquista pudo no ya institucionalizarse, sino

\footnotetext{
1 Richards (1999); Cenarro (1998); Casanova - Moreno Gómez - Espinosa - Mir (2002); Preston (2011).

2 Maquiavelo (1999).

3 Marx (1976).

4 Nietzsche (1994).

5 Benjamin (1973).
} 
además mantenerse en el tiempo, gracias a la articulación de toda una serie de dispositivos disciplinarios - orientados a la disciplinarización de las conductas individuales $^{6}$ - y reguladores - destinados a la ordenación de los fenómenos poblacionales de conjunto ${ }^{7}$, capaces de crear determinadas imágenes de sí mismo, de los demás y del mundo en una gran parte de la sociedad española de la época. En este sentido, sólo la efectividad de todo ese agregado de dispositivos biopoliticos - disciplinarios y reguladores- orquestados por el nuevo régimen, y su capacidad para articular determinadas formas de conducción de conductas - a su vez competentes para elaborar ciertos modelos de subjetividad-, pudo permitir el sostenimiento de la dictadura ${ }^{8}$.

En efecto, si el régimen franquista fue capaz de perdurar en el tiempo -máxime teniendo en cuenta las circunstancias en las que se fundó-, fue precisamente por su capacidad para generar - a través de sus diferentes dispositivos biopoliticos - una forma de subjetividad característica del español de aquella época, un individuo resignado a sus circunstancias, paciente, pasivo, a-politizado, sumiso, un sujeto ideal al que podríamos referirnos como el homo patiens ${ }^{9}$. Este individuo paradigmático de la posguerra española, verdadera obra predilecta del régimen, fue sin duda el basamento sobre el que se sostuvo aquel sistema político nacido de los trágicos aconteceres de una cruenta y brutal guerra civil. Y es que con la creación de una población sumisa, productiva al tiempo que sometida, resignada a sus circunstancias y al silencio de la vida cotidiana, el régimen se estaba asegurando un largo período de estabilidad política y social -sin olvidar, insistimos, la efectividad de los siempre presentes aparatos represivos del Estado, por utilizar la expresión althusseriana ${ }^{10}$.

Ahora bien, y llegados a este punto, cabe preguntarnos por las variaciones acaecidas en los distintos dispositivos biopoliticos y la propia gubernamentalidad franquista -entendiendo por forma de gobierno o gubernamentalidad la "forma de conducción de conductas dentro de unas coordenadas históricas concretas"11_, articulados por el régimen en su larga trayectoria, así como por sus actuaciones y efectos en la población. En este sentido, todos los historiadores del franquismo convienen

\footnotetext{
6 Atendiendo únicamente a la teoría foucaultiana que aquí nos sirve de inspiración metodológica y conceptual, y principalmente: Foucault (2005).

7 Para esto: Foucault (2005), pp. 143-169; Foucault (1997), pp. 213-235; Foucault (2004a).

8 Una breve introducción metodológica y conceptual, un análisis del nacimiento de la biopolítica franquista y sus particularidades hasta principios de los años cincuenta, de la extensión de todo un conjunto de dispositivos biopolíticos idiosincrásicos del régimen en aquellos años, y de la creación de un tipo de subjetividad característica del español de la posguerra, en: Cayuela Sánchez (2009); véase también Cayuela Sánchez (2008a).

9 Cayuela Sánchez (2009).

10 Althusser (1974).

11 Foucault (2004a), p. 92.
} 
en señalar la importancia que para cualquier estudio sobre el régimen adquiere el hecho de su dilatada historia, flanqueada por continuos cambios de profundas significaciones. Por todo ello, pretendemos aquí elaborar un análisis del funcionamiento y características propias de los principales dispositivos disciplinarios y reguladores articulados por el régimen franquista para el período comprendido entre 1959 -la puesta en marcha del famoso Plan de Estabilización- y 1975 -año de la muerte del dictador. Para esto distinguiremos tres ámbitos de análisis: el ámbito económico, para el que tendremos en cuenta determinados mecanismos disciplinarios y reguladores de capital importancia para nuestros intereses demostrativos; el ámbito médico-social, donde analizaremos de forma somera algunos dispositivos de control sanitario y psicológico; y por último, el ámbito ideológico, donde atenderemos al funcionamiento de algunos de los conocidos por Althusser como aparatos ideológicos del Estado, entendidos como los mecanismos encargados de legitimar un determinado statu quo "mediante la ideología", y entre los que cabría destacar el religioso, el escolar, el familiar o el jurídico, entre otros 12 .

En última instancia, el análisis del funcionamiento y efectividad de todos estos dispositivos biopolíticos deberá mostrar: por un lado, la configuración de una forma de gobierno - o gubernamentalidad - propia del franquismo desarrollista; por otro lado, la creación o continuación de unas determinadas formas de subjetivación características de la España del período, en ruptura más o menos evidente con aquellas otras analizadas para el primer franquismo y que tuvieron como resultado la creación de nuestro homo patiens; y por último -aunque conectado con lo anterior-, el surgimiento y extensión por todo el cuerpo social de toda una serie de resistencias -existentes según Foucault en toda relación de poder y que cabría entender como las estrategias que invierten el orden establecido o violentan la norma ${ }^{13}$ - que determinarán, como no podía ser de otro modo, el debilitamiento del régimen y la aparición de nuevas formas de subjetivación, señalando todo ello a su vez el nacimiento de una nueva gubernamentalidad en la España del último cuarto del siglo XX.

\section{El neocapitalismo y la organización científica del trabajo llegan a España: el ámbito económico}

Desde principios de los años cincuenta, la dictadura se vio obligada a suavizar sus totalitarias pretensiones económicas, guiada fundamentalmente por ese instinto de supervivencia tan característico del franquismo. En 1948 llegó el primer cré-

12 En este punto, seguiremos el esquema trazado en un trabajo anterior sobre la biopolítica del primer franquismo: Cayuela Sánchez (2009), 275 ss.

13 Foucault (1987). 
dito privado del National City Bank estadounidense, en 1950 España entró en la FAO, y ese mismo año el Congreso Americano aprobó el primero de sus créditos con fines civiles para nuestro país, en una versión reducida y exclusiva del Plan Marshall. En 1952 se suprimió la cartilla de racionamiento, y un año después se firmaron los famosos pactos militares con Estados Unidos, pactos que desembocarían en la entrada de España en la ONU en 1955. Todo ello permitió a los dirigentes españoles ensayar -en el plano económico- una cierta política económica mercantilista que, a pesar de mejorar inicialmente las condiciones materiales del país, se revelaría a corto plazo como absolutamente inviable. Así, y ya desde mediados de los años cincuenta, la conocida como industrialización mercantilista -basada en una política de sustitución de importaciones, unos tipos de cambio múltiples y en un proceso de intensa inversión pública-, parecía llegar a su fin. Se produjo entonces un fuerte desequilibrio económico y financiero, unido a un alarmante aumento del déficit público, un acelerado proceso inflacionista y un desbordamiento incontenible del déficit exterior ${ }^{14}$, circunstancias económicas adversas que provocaron un creciente descontento que empezaba a amenazar esa paz social impuesta por el régimen desde la Guerra Civil.

Todo esto convenció a los dirigentes franquistas de la necesidad de iniciar contactos con la Organización Europea de Cooperación Económica (OECE) y el Fondo Monetario Internacional (FMI), como primer paso para la incorporación de España al concierto económico internacional. Con la aceptación de la ayuda técnica y financiera de ambos organismos, el gobierno español asumía no obstante la desmantelación del dispositivo autárquico franquista - uno de los pilares fundamentales de los regímenes fascistas y/o totalitarios $15_{-}$, y la apertura de la economía española al exterior. Así, en el verano de 1959 se aprobaba el famoso Plan de Estabilización económica, estructurado en función de seis ejes concretos de actuación 16: en primer lugar, la recuperación y endurecimiento de la política monetaria; en segundo lugar, la restricción del crédito al sector privado; en tercer lugar, la extensión del límite del crédito al sector público; en cuarto lugar, la consolidación fiscal, perseguida mediante un aumento de los ingresos públicos y la presión fiscal; en quinto lugar, la regulación de los volúmenes de importación; y finalmente, el establecimiento de un tipo de cambio único para las transacciones.

Lo que la entrada en vigor de tales medidas estabilizadoras suponía era, precisamente, la renuncia por parte de las autoridades franquistas del control económico del país, dejando a los agentes económicos libertad de maniobra y suprimiendo progresivamente el comercio intervenido por el Estado. Además, y junto a esta apertu-

\footnotetext{
14 González (1999), p. 134 ss.

15 Véase: Foucault (2004b), p. 113; una introducción general a las políticas económicas de los países fascistas en: Cipolla (1980).

16 Carreras y Tafunell (2003), pp. 327 ss.
} 
ra comercial al exterior ${ }^{17}$, se produjo una apertura financiera ${ }^{18}$ que a la larga supondría uno de los pilares fundamentales del llamado milagro económico español de los años sesenta, debido a toda una serie de ventajes que los inversores extranjeros no podían desaprovechar: la proximidad a Europa; los bajos salarios; una escasa conflictividad social; una legislación más que favorable, etc. Además, el fuerte flujo migratorio hacia los países del norte y centro de Europa iba a suponer para la España de los años sesenta una importante fuente de divisas ${ }^{19}$, a las que habría que unir las procedentes del incipiente sector turístico ${ }^{20}$, consolidado ya en aquellos años como una de las grandes industrias del país. Todo ello permitió de hecho que la economía española creciera entre 1960 y 1973 con un ritmo de incremento medio del 7,9\% del PIB y del 6,9\% per cápita-crecimiento únicamente superado en la época por Japón.

La llegada del neocapitalismo ${ }^{21}$ a España y el fuerte crecimiento económico que experimentó el país desde principios de los años sesenta, trajo consigo toda una serie de consecuencias tremendamente importantes para las cuestiones que aquí nos ocupan. Así, y en primer lugar, exigió la implantación progresiva de los métodos propios de la llamada organización científica del trabajo, lo que suponía la consolidación de un fuerte proceso de intensificación laboral22. La fijación de los ritmos de trabajo, la determinación previa de los rendimientos óptimos y normales -así como la asignación de un nivel salarial relativo al rendimiento-, o el reconocimiento de la calificación profesional, fueron elementos introducidos en el país por aquel entonces. No obstante $-\mathrm{y}$ a diferencia de lo ocurrido en otros países del ámbito europeo-, en España no se produjeron aumentos salariales en niveles semejantes a los incrementos de productividad -aplicándose tales medidas a coste cero-, lo que unido a las elevadísimas jornadas laborales supuso a la larga un galopante incremento del descontento social, un descenso progresivo de los mismos niveles de productividad, así como sendos problemas en los procesos de negociación colectiva. De hecho, y como señalan Molinero e Ysàs, «en la negociación de los convenios no se discutían mejoras globales de productividad sino cambios que repercutían en la intensificación del trabajo» 23 .

\footnotetext{
17 Serrano Sanz y Pardos (2002), pp. 369-395.

18 González (1999), p. 217 ss.

19 Oporto del Olmo (1992).

20 Pellejero (1999).

21 Es preciso señalar aquí que con el término neocapitalismo no nos queremos referir al neoliberalismo financiero actual, sino al sistema económico de libre mercado, posterior a la II Guerra Mundial, y que otorga al Estado un papel activo en los procesos de producción, la reproducción económica o la propia política social.

22 Sobre estas cuestiones, véase: Sennett (2001); también, aunque algo restringido en nuestra opinión al ámbito francés: Boltanski y Chiapello (2002); y para el caso español: Vegara (1971).

23 Molinero e Ysàs (1998), p. 85.
} 
En este sentido, la incapacidad productiva española fue solventada por unas cotas elevadísimas de intensificación del trabajo, lo que a la larga lastraría por otra parte las inversiones destinas a mejorar la eficiencia de las empresas. De este modo, los trabajadores se veían obligados a ampliar su jornada laboral para hacer frente a las fuertes demandas sociales de bienes de consumo que hicieran su vida más confortable, en el marco de la naciente sociedad de consumo española24. En aquella época de esplender económico, los empresarios amasaron grandes fortunas, mientras que la participación de los salarios en el PIB apenas aumentó durante toda la década de los sesenta. Ello resulta tremendamente curioso puesto que, si el régimen franquista aceptó de hecho la entrada del neocapitalismo en España y la renuncia a la tan cacareada autarquía económica, fue precisamente para atajar la creciente conflictividad social en aumento desde mediados de los años cincuenta: todos olvidarían sus reivindicaciones políticas -pensaban los jerarcas del régimen- si llegaban a tener en sus casas una lavadora, una nevera y, más aún, un aparato de televisión o un coche.

Pero -y ya para terminar con este apartado-, ¿cuál era el papel asignado en este nuevo sistema económico a aquel Sindicalismo Vertical ensayado en España desde los primeros años cuarenta, aquel dispositivo disciplinario idiosincrásico del mundo laboral durante el primer franquismo?25 Lo cierto es que -y si bien nunca llegó a ser el mecanismo de encuadramiento al que aspiraba en sus comienzos- continuó con sus funciones principales de control de la clase trabajadora, aunque disminuyendo progresivamente su capacidad e incluso sirviendo de base para las nuevas y legítimas reivindicaciones obreras, sobre todo a través de los sindicalistas comunistas y socialistas infiltrados en su estructura. De hecho, ya con la entrada en vigor de la famosa Ley de Convenios Colectivos de 1958, el franquismo había certificado su renuncia a organizar un sistema laboral autoritario de asignación de salarios y de reglamentaciones del trabajo. La nueva situación económica no lo permitía, y además era preciso el aumento salarial con el fin de frenar la galopante conflictividad laboral por un lado, y potenciar la demanda interna -fuente de crecimiento económico- por otro. Se apostaba entonces desde la Organización Sindical Española (OSE) por un sindicalismo de participación que regulase la comunicación entre empresarios y trabajadores, como institución social con fines propios y específicos encargada de jugar el papel principal en la regulación de la convivencia social, y tanto a nivel productivo como administrativo dentro de las empresas 26 .

No obstante, la aparente apertura progresista de la legislación laboral franquista tenía como objetivo fundamental eximir al Estado de cualquier responsabilidad

\footnotetext{
24 Miguez; De Miguel; Jiménez Blanco; Castilla del Pino; Vázquez Montalbán; Aguirre; Chamorro y Fernández Alba (1969).

25 Véanse al respecto los trabajos de: Ludevid (1976); Aparicio (1980); y también Sánchez Recio (2002).

26 Ludevid (1976), p. 38.
} 
en cuanto a los problemas laborales se refería. Y ello porque con la nueva legislación, el conflicto quedaba entre patronos y trabajadores, permaneciendo los mecanismos estatales al margen del proceso de negociación colectiva, e interviniendo solamente en caso de absoluta necesidad -esto es, ante una posible alteración del orden público.

\section{La «Eubiatría» de la Raza hispánica y el nacimiento de la Biopolítica social en España: el ámbito socio-sanitario}

Ya desde mediados de los años cincuenta, el conocido Seguro Obligatorio de Enfermedad (SOE) - mecanismo regulador en torno al que se había estructurado el modelo asistencial auspiciado por el primer franquismo-, parecía un proyecto enteramente agotado, y ello a pesar de las continuas reformas a las que se vio sometido durante toda la década27. Ello fomentó, ya desde finales de los años cincuenta $-\mathrm{y}$ junto a todo un conjunto de presiones tanto internas como externas al ámbito nacional-, la multiplicación de informes, estudios, encargos y planes destinados a promover la discusión pública sobre los evidentes problemas del SOE y sobre la necesidad de planificación de un verdadero sistema de Seguridad Social -acorde ya con los ensayados en otros países de Europa durante la segunda posguerra mundial. Tras no pocas resistencias - provenientes tanto de determinados sectores del gobierno como de una buena parte de los profesionales médicos y compañías de seguros, que veían seriamente amenazadas sus lucrativas fuentes de ingresos-, un nuevo dispositivo socio-sanitario fue aprobado en forma de Ley de Bases de la Seguridad Social en diciembre de 1963, permitiendo el inicio de una nueva etapa socio-sanitaria caracterizada por el paso de un conjunto más o menos heterogéneo de Seguros Sociales a un verdadero sistema de Seguridad Social ${ }^{28}$. De este modo, se estaba asumiendo en España el -hasta entonces ajeno al régimen- principio de la solidaridad comunitaria para el sistema de reparto, además de otros elementos muy significativos entre los que hay que destacar: la consolidación de la participación del gobierno en los órganos gestores de la sanidad pública; la supresión en la gestión de la sanidad del ánimo de lucro; la consideración conjunta de todas las contingencias y situaciones objeto de protección; la creciente participación del Estado en la financiación de las prestaciones sociales -lo que suponía de hecho la definitiva socialización de la medicina en nuestro país; la ampliación del campo de aplicación a todos los ciudadanos - al menos en principio; y la sustitución del concepto de riesgo -característico de etapas anteriores-por el de contingencia -propio de la medicina social del Welfare State 29.

27 Alberti López (1985), pp. 297-338.

28 Véase Muñoz Machado (1975), p. 173 y ss.

29 Sobre el Estado del Bienestar, véase Esping-Andersen (1993); y Esping-Andersen (2000). 
Con todo ello el régimen franquista parecía querer asumir -al menos en parteel modelo social ensayado en la Europa de la segunda posguerra mundial, un Estado del Bienestar basado en la creación de una red de dependencias mutuas que asegurara un mínimo de bienestar para los ciudadanos en caso de infortunio -en el marco de una economía de libre mercado, como acabamos de ver en el apartado anterior. Por supuesto, tal modelo estatal -y su forma característica de Biopolítica social ${ }^{30}$, perseguía rentabilizar en términos de legitimidad política las importantes aportaciones estatales en el ámbito socio-sanitario, conteniendo así el auge del comunismo en España y manteniendo en niveles aceptables los conflictos sociales y obreros. Este objetivo no siempre confesado por los artífices del Welfare State -en gran medida impuesto a los países europeos por los Estados Unidos tras la II Guerra Mundial para frenar el auge del comunismo y una posible expansión de la Unión Soviética al oeste-, motivó igualmente los esfuerzos de los jerarcas franquistas, también presionados por los organismos internacionales que les habían apoyado financiera y técnicamente en la aplicación del Plan de Estabilización. Por supuesto, en la España del franquismo no existían los derechos y las libertades políticas básicas ${ }^{31}$, pero ello no importaba. El régimen del General Franco seguía siendo un aliado inestimable contra el comunismo, y las estrategias de legitimación ensayadas en otros países democráticos de Europa podían servir igualmente en nuestro país, e incluso a un coste mucho más bajo.

No obstante, y esto es lo realmente interesante aquí, la adopción de este tipo de dispositivo socio-sanitario -mecanismo regulador característico de la Biopolítica social del Estado del Bienestar-, supuso la incorporación definitiva del país a ese proceso de despegue médico iniciado en Europa allá por el siglo XVIII. Al tiempo, estaba extendiéndose en España una determinada concepción de la medicina instalada ya en otros países desarrollados desde hacía algunos años, una nueva concepción no relacionada únicamente ni con las enfermedades ni con los enfermos. A ello se refería Foucault del siguiente modo: «Tomando como referencia el Plan Beveridge, se observa, en el decenio 1940-1950, la formulación de un nuevo derecho, de una nueva moral, de una nueva economía, de una nueva política del cuerpo [...] Desde entonces, el cuerpo del individuo es uno de los objetivos principales de la intervención del Estado, uno de los grandes objetos de los que el propio Estado debe hacerse cargo» ${ }^{32}$. En este sentido, asistimos - con el mismo advenimiento del Estado del Bienestar- al surgimiento de un nuevo concepto de salud en una etapa

\footnotetext{
30 Cayuela Sánchez (2008a), pp. 33-49.

31 De hecho, se trata de una estrategia ensayada ya en la Alemania de Bismarck, donde -y en contra de las tesis de T. H. Marshall- se concedieron toda una serie de derechos sociales en parte para apaciguar el descontento de las clases trabajadoras, negando al tiempo la concesión de los plenos derechos políticos que estaban reclamando.

32 Foucault (2002), p. 346.
} 
caracterizada, tanto cualitativa como cuantitativamente, por la extensión de la medicina a ciertos ámbitos que anteriormente le habían sido completamente ajenos 33 .

En la España del tardofranquismo -y en un movimiento sorprendentemente asimilable al acaecido en otros países del ámbito europeo aún por estudiar-, el gasto público en salud comenzaba a crecer más deprisa que la misma riqueza estatal, lo que estaba obligando de hecho al Estado franquista a incrementar la presión fiscal para poder así destinar una cantidad cada vez mayor de recursos económicos al área sanitaria. Por supuesto, las prestaciones sociales no eran comparables a las desplegadas en países como Francia, Alemania o Dinamarca -aunque de hecho no fueran tan distintas de las de otros países del arco mediterráneo como Portugal o Italia. Pero lo realmente interesante era cómo un régimen al menos autoritario -por no entrar aquí en disputas historiográficas-, se vio obligado a hacer frente al problema generado por el crecimiento ininterrumpido de los gastos sanitarios derivado, no ya sólo de las propias reformas internas del sistema, sino de la demanda de los usuarios, imbuidos por unas determinadas concepciones de la salud completamente novedosas y extrañas hasta entonces en España. Una determinada concepción de la medicina, propia como decimos de la Biopolítica social del Welfare State, había penetrado no sólo en el mismo sistema sanitario español, sino en las conciencias de una gran parte de la sociedad española, provocando profundos cambios en las estrategias gubernamentales del régimen.

Al tiempo, se había producido definitivamente en España la llamada transición demográfica, sobre todo debido -junto a los avances médicos de la época, claro está- a la capacidad de los profesionales de la medicina y a ciertos dispositivos como las Cátedras Ambulantes de la Sección Femenina -muy activas durante los años cuarenta aunque en clara decadencia ya desde los primeros cincuenta-, para extender a todo el cuerpo social las normas y principios sanitarios e higiénicos bási$\cos ^{34}$. Todo ello es de hecho una clara muestra de cómo la atención a la enfermedad había suplantado a la vigilancia higiénica propia de la biopolitica intervento$\mathrm{ra}^{35}$, abandonando los principios de intervención médico-social hasta entonces vigentes. Estamos, en efecto, ante el triunfo de la medicalización en España, tanto en la extensión del número de profesionales, como en la cobertura asistencial e incluso la preferencia popular36: había sucumbido por fin en nuestro país aquel homo hygienicus propio del Estado interventor de finales del siglo XIX y principios del $\mathrm{XX}^{37}$. En este sentido, durante el primer franquismo se continuó el esfuerzo ini-

\footnotetext{
33 García Capilla (2007), p. 110.

34 Rodríguez Ocaña (1999), pp. 19-42; también Reher (2003), pp. 11-26; y para un estudio en perspectiva Gómez Redondo (1992).

35 Vázquez García (2009), p. 201 ss.; y también Cayuela Sánchez (2008b).

36 Rodríguez Ocaña (1999), pp. 45-46.

37 Labisch (1985).
} 
ciado en España desde principios del siglo pasado, esfuerzo que cristalizó -como decimos- en la culminación de la transición demográfica ya en los años sesenta. Así, el drástico descenso de la mortalidad infantil -unido a otros factores como el aumento de la fecundidad, la natalidad y la nupcialidad-, permitió un intenso crecimiento demográfico sobre todo desde la década de los años cincuenta, crecimiento que hizo que la población española pasara de 26 millones de habitantes a comienzos de los años cuarenta, hasta los casi 35 millones a mediados de los años setenta. Se trataba en efecto de un crecimiento no tan acusado como el acaecido en otros países desarrollados en aquellos años, pero no obstante ponía de manifiesto el éxito relativo de los dispositivos reguladores orquestados por el franquismo desde los primeros años cuarenta -además de los importantes avances sanitarios y farmacológicos del período, claro.

Por último, en lo que se refiere al dispositivo psiquiátrico activado -o mejor reactualizado- en estos últimos años del franquismo, podemos afirmar que siguió manteniendo muchos de los prejuicios ideológicos, religiosos, morales, racistas y antiorganicistas de los años cuarenta y cincuenta ${ }^{38}$. El antimaterialismo siguió estando muy presente entre los psiquiatras españoles del período, tendentes en muchos casos a una tomización de la psiquiatría ciertamente peculiar. Por supuesto, Freud y el psicoanálisis seguían siendo absolutamente rechazados por la psiquiatría oficial -llegando a ser considerada la corriente psicoanalítica por el eminente doctor Sarró de puro neosionismo ${ }^{39}$-, pues se trataba de una doctrina que perseguía liberar las fuerzas más oscuras y demoníacas del hombre, auténtico origen de los impulsos revolucionarios. La psiquiatría española era por aquel entonces una auténtica psiquiatría del orden, entendida como la ciencia de la eubiatría de la raza hispánica, encargada de domeñar las necesidades materiales e instintivas del hombre en aras de una perfección moral acorde con la doctrina cristiana y católica 40 .

Por supuesto, las circunstancias sociales seguían siendo negadas como posible origen de los trastornos mentales, y de hecho, el enfermo mental seguía siendo considerado como el único culpable de su problema: si el hombre no es lo suficientemente fuerte la personalidad sana se resquebraja, dejando aflorar las contradictorias pulsiones del individuo en forma de enfermedades mentales. Como señala González Duro, «Según esta curiosa línea de pensamiento, inmanentista y fatalista, la problemática de la enfermedad psíquica se simplifica al máximo, y se la desconecta por completo del medio social en el que el individuo que la padece vive. La conclusión es muy significativa: la organización social es perfecta, y no tiene que cambiar para que alguien deje de sufrir o no llegue a sufrir» ${ }^{41}$. Todo ello supuso de hecho el desa-

\footnotetext{
38 González Duro (1978), p. 69 ss.; véase también Castilla del Pino (1977), pp. 79-102.

39 González Duro (1978), p. 98.

40 López Ibor (1964).

41 González Duro (1978), p. 81.
} 
rrollo de una especie de psicoterapia nacional que ordenó, a su vez, un cierto tipo de terapéutica nacional, sustentada en una teoría jerárquica de la sociedad en referencia constante a los supuestos pilares de la cultura y la personalidad hispánica, el rechazo a los psicofármacos y, ya en los años sesenta, muy influenciada por las teorías conductistas.

Pero todo ello no es de extrañar. Como ya había hecho desde principios de los años cuarenta, la psiquiatría franquista debía seguir cumpliendo la función de encasillar, localizar, controlar y marginar a aquellos individuos supuestamente ajenos a la Raza Hispánica. Entonces fueron los rojos, ahora, en el nuevo contexto del neocapitalismo, los individuos incapaces de producir. La única función del dispositivo psiquiátrico franquista seguía siendo la institucionalización de una agencia de control de las conductas entendidas como desviadas, fundada en una interpretación de la enfermedad mental guiada por todo un sistema de valores y creencias garante del orden social vigente. En este sentido, la psiquiatría franquista no varió en exceso sus discursos con el desarrollismo, dejando al margen eso sí las antiguas proclamas en pro de la pureza racial de España, pero legitimando científicamente las desigualdades sociales derivadas del orden social establecido por Dios en la Tierra y por las propias jerarquías naturales.

\section{Hacia un nuevo sistema de creencias: el ámbito ideológico}

Ya desde mediados de los años cincuenta, pero sobre todo a partir de principios de los sesenta, la situación de optimismo generalizado entre los dirigentes franquistas y una buena parte de la sociedad española -optimismo derivado de los cada vez más evidentes signos de despegue económico-, iba a permitir una cierta relajación en el aparato represivo y censor del régimen. Toda una serie de influencias culturales se filtraban por las cada vez más porosas fronteras españolas, ante el relativo beneplácito de las autoridades de un régimen necesitado de una mayor integración en el contexto europeo, pero también consciente del hecho de que tales influencias podían acarrear una pérdida de legitimidad difícilmente recuperable ante la nueva sociedad española ${ }^{42}$. Como se demostró durante las famosas celebraciones de los $X X V$ Años de Paz, la Guerra Civil seguía siendo la fuente de legitimidad primitiva ${ }^{43}$, relativamente enmascarada ya por la aparente y en muchos sentidos real estabilidad política del régimen, así como por los significativos avances económicos del período. En este sentido, resulta revelador constatar que no fue hasta 1963 que las autoridades franquistas declararan la prescripción de todos los delitos cometidos durante la guerra, y que la propia Ley de Responsabilidades Politicas permaneciera de hecho vigente hasta 1966.

\footnotetext{
42 Ruiz Carnicer (2001), pp. 283-318.

43 Véase al respecto: Aguilar Fernández (1996).
} 
En cualquier caso, el régimen seguía controlando los medios de comunicación tradicionales, a los que había que añadir, ya desde inicios de la década de los sesenta, la televisión, sin duda el gran vehículo informativo de la segunda mitad del siglo $\mathrm{XX}^{44}$. La televisión se había convertido en efecto desde mediados de los sesenta en un medio potente y fascinante, y las autoridades franquistas no iban a dudar utilizarlo en beneficio propio. Junto a informativos y programas especiales decididamente orientados al adoctrinamiento político, se emitían espectáculos televisivos -películas, concursos, dibujos animados, etc.- manifiestamente banales cuya única misión era el entretenimiento y la desmovilización, tal y como ocurría -y ocurrepor otra parte en cualquier otro país del mundo. No obstante, y esto sí que es destacable, la Televisión Española era por aquel entonces un organismo centralista, aislado totalmente de sus homólogos europeos y occidentales. En este sentido, TVE podía considerarse de hecho como un ejemplo paradigmático del modelo de televisión característico de los países totalitarios, donde la televisión nacional depende absolutamente del gobierno central.

De hecho, aunque otros medios -fundamentalmente la radio $45_{-}$vivieron desde los años sesenta un fuerte movimiento expansivo - con una pluralidad empresarial y de iniciativas que la televisión no podía ni imaginar-, el control de los medios de comunicación siguió siendo una misión prioritaria para las autoridades, preocupadas como siempre por el sostenimiento del régimen. Buena muestra de ello fue la famosa Ley de Prensa de 1966, promulgada por el gabinete de Manuel Fraga Iribarne y que eliminaba la censura previa -aplicándose sobre los productos culturales a posteriori si fuera necesario-, y que no suponía en realidad más que una vuelta de tuerca que obligaba a interiorizar los principios del Movimiento a los creadores $-\mathrm{O}$ al menos amoldar sus obras a aquellos.

Ahora bien, ¿qué sucedió en aquellos convulsos años de desarrollo económico con los llamados organismos frontales de encuadramiento como el Frente de Juventudes o la Sección Femenina de Falange ${ }^{46}$ ? ¿Qué cambios acaecieron en el sistema educativo español en aquel período de expansión económica? En lo que se refiere al Frente de Juventudes -que pronto pasaría a denominarse Organización Juvenil Española-, todo parece indicar que ya desde finales de los años cincuenta marchaba por lo general desfasado con respecto a la evolución de la sociedad española, cuanto más si nos referimos a los nuevos valores, intereses y perspectivas de los jóvenes ${ }^{47}$. El principal objetivo de la OJE en aquellos postreros años del régimen seguía siendo no obstante el encuadramiento y la formación en los principios

\footnotetext{
44 Para España, véanse los estudios de: Palacio (2005); y Bustamante (2006).

45 Díaz (1997).

46 Ruiz Carnicer (2001), p. 313 ss.

47 Sáez Marín (1988), p. 185; también coincide con esta afirmación otro gran estudioso del organismo falangista como Parra Celaya (2001), p. 125 ss.
} 
del Movimiento de la juventud española, y ello a pesar del cambio de talante general de la organización. En este sentido, seguía preocupada por inspirar en sus afiliados los valores de la autoridad y la disciplina, el compromiso con el ideario político, el reconocimiento y el respeto de la libertad de cada uno o la satisfacción del trabajo bien hecho, pero también el compromiso, la iniciativa, la responsabilidad, etc. Se trataba de hecho de una scautización de la organización, donde la formación política seguía siendo de gran importancia, pero entendida ahora dentro del marco de la formación general de la personalidad del individuo. En muchos sentidos, el carácter ideológico nacionalsindicalista de la organización no varió, pero se vio obligado -como el propio Movimiento- a amoldarse a los nuevos tiempos. Con todo, podemos afirmar sin temor a equivocarnos que fracasó en su inicial labor de formación y encuadramiento de la juventud española, corriendo de hecho la misma suerte que el falangismo que lo inspiró: permanecer eternamente en el estado de revolución pendiente.

En lo que respecta a la Sección Femenina de Falange48, hay que señalar que entró en claro declive ya desde 1957, cuando sus más firmes aliados en el Gobierno -Arrese, Girón de Velasco y otros destacados falangistas- fueron sustituidos por los tecnócratas del Opus Dei. Ello no impidió no obstante que siguiera su labor hasta incluso 1977, sobre todo por el hecho de que su campo de acción no era disputado por ninguna fuerza política del régimen -excepto por Acción Católica-, y que su labor de adoctrinamiento de las mujeres no podía ser en absoluto contraproducente para los intereses estatales. Con todo, el desarrollo económico iba a traer consigo toda una serie de cambios en la mentalidad de las mujeres españolas, mucho más preocupadas por el desarrollo, el bienestar y la felicidad auspiciados por la nueva sociedad de consumo, que por los ideales de mujer que promulgaba la organización falangista. Además, sus programas intervencionistas socio-sanitarios, de gran beneficio en los años cuarenta, fueron progresivamente sustituidos por el trabajo asistencial y educativo institucionalizado más propio de los nuevos tiempos. Y aunque las autoridades de la Sección Femenina pretendieron de hecho enarbolar la bandera de un mundo más justo para las mujeres desde principios de los años sesenta -en un claro intento por revitalizar la organización y ganar apoyo social-, su influencia sobre las formas de ser y pensar de las mujeres españolas fue disminuyendo a medida que el régimen agonizaba.

Por último, en lo que se refiere al sistema educativo en esta etapa del franquismo desarrollista, es preciso apuntar que sufrió toda una serie de remodelaciones orquestadas al ritmo de los profundos cambios sociales y económicos del período 49 . En efecto, presionadas por los organismos internacionales que hicieron posible la

48 Véanse los trabajos de Sánchez López (1990); y Richmond (2004).

49 Puelles Benítez (1999), p. 319 ss.; y también Navarro Sandalinas (1990), p. 168 ss. 
puesta en marcha del Plan de Estabilización ${ }^{50}$, las autoridades franquistas debieron entender que el desarrollo económico sostenido sólo sería viable si el sistema educativo español era capaz de crear el capital humano suficiente para abastecer de mano de obra preparada a la naciente industria nacional. Para ello se acometieron toda una serie de reformas del sistema educativo orientadas, en primer lugar, a acabar con el analfabetismo - que alcanzaba cotas del 25\% a mediados de la década de los cincuenta-, y después - como decimos- a proporcionar a la nueva economía nacional la necesaria mano de obra cualificada. En efecto, como señala Navarro Sandalinas, entonces «No se alfabetizó con más intensidad porque cambiaran los principios ideológicos de la clase dominante; no se potenció la enseñanza primaria porque el bloque de poder tuviera interés en la cultura popular. Se hizo porque el sistema imponía sus condiciones si se deseaba el apoyo financiero a la economía española, y porque dijo alguien al régimen que ésta no podía funcionar sin una mano de obra especializada» 51 .

\section{La gubernamentalidad del franquismo desarrollista y el nacimiento de nuevas formas de subjetivación}

Las interacciones entre los tres ámbitos analizados aquí -a saber, el económico, el socio-sanitario y el ideológico- van a mostrar, en efecto, las notas características de aquello a lo que nos hemos venido refiriendo como gubernamentalidad tardofranquista. En este sentido, los dispositivos biopolíticos orquestados por el régimen para cada una de estas tres esferas de la vida humana ${ }^{52}$ han de señalar, en su mismo funcionamiento, la forma en que la dictadura franquista gobernó el orden de los bienes, de los cuerpos y de las mentes durante aquellos sus últimos años, generando formas de conducción de conductas características. En un juego infinito de relaciones recíprocas, fluctuantes y mutuamente interconectadas, estos tres ámbitos revelan en su misma ordenación cómo un conjunto ilimitado de relaciones de poder productivas -dirigidas en mayor o menor medida por los distintos dispositivos biopolíticos franquistas-, marcaron las formas de ser y pensar de los españoles de la época, las maneras de entenderse a sí mismos, a los demás y al mundo en que les tocó vivir. Al tiempo, las decisiones adoptadas por el régimen en cada uno de estos ámbitos produjeron igualmente toda una serie de consecuencias no deseadas que, junto con una infinidad de resistencias - no sólo a los modelos de subjetividad franquistas sino mediante huelgas, protestas callejeras, actitudes de rebeldía cotidianas, etc.-, iban a provocar precisamente el derrocamiento de la dictadura y la aparición

50 VV. AA. (1962), p. 543 ss.

51 Navarro Sandalinas (1990), p. 202.

52 Véase Campillo (2001). 
de nuevas formas de subjetividad y, ya en la democracia, de un tipo distinto de gubernamentalidad.

Así, si atendemos a los efectos de la apertura económica y la llegada de la economía de libre mercado a España posibilitada por la puesta en marcha del Plan de Estabilización de 1959, debemos señalar, en primer lugar, el afloramiento de la sociedad de consumo española, generando al tiempo un aumento en las expectativas materiales de la población. El régimen había comprendido que sólo el desarrollo económico y la mejora del nivel de vida de los españoles permitirían su sostenimiento, pero eso era precisamente lo que a la larga generaría en una buena parte de la población los deseos de libertad que iban a finiquitar -al menos aparentementeaquel sistema político. En efecto, al abrirse las fronteras no sólo se importaron -y exportaron- mercancías, sino también imágenes de lo real y formas de vida que poco o nada tenían que ver con la experiencia cotidiana de los españoles. La abundancia europea y occidental era perceptible no ya sólo en los filmes estadounidenses, sino en las costas mediterráneas y en las ciudades históricas, abarrotadas por turistas europeos que, para asombro de los lugareños, no eran sino albañiles, conductores de autobús o peluqueros. Y formas de vida que también comenzaban a exhibir ante sus paisanos esos cientos de miles de españoles que emigraron a Europa en busca de una vida mejor, una vida que, a fin de cuentas, sí era posible.

Pero además, la implantación del nuevo orden económico en España suponía, incluso como exigencia del FMI y la OECE, una mejora sustancial tanto del sistema educativo como del Sistema de Seguridad Social. Así, y por un lado, la necesidad de mano de obra cualificada para la nueva economía obligó a las autoridades franquistas a invertir cuantiosas sumas de dinero en el sistema educativo en todos sus niveles, lo que iba a permitir la extensión de un cierto nivel cultural en una porción cada vez más amplia de la sociedad española, posibilitando no sólo el desarrollo económico sino también la generación de toda una serie de expectativas democráticas ya muy extendidas desde los primeros años setenta. En efecto, el aumento del número de estudiantes y la procedencia social variada de los mismos, permitió el desarrollo de un movimiento contestario estudiantil con unas actitudes vitales muy distintas a las promulgadas por el régimen a través -por ejemplo- de la Organización Juvenil Española.

Pero además, y por otro lado, la exigencia de estructurar un Sistema de Seguridad Social equiparable al menos al del resto de los países del ámbito europeo mediterráneo. Lo que ello suponía era, en primer lugar, una reforma profunda del régimen fiscal que permitiera las ingentes inversiones necesarias para ponerlo en práctica, reforma acometida no ya en beneficio de las grandes rentas -hasta entonces los mayores beneficiados por el régimen-, sino de las clases populares. Por supuesto, el sistema de seguridad social español-como ya apuntamos y al igual que en el resto de Europa-, era un mecanismo legitimador ideado principalmente para 
atajar la conflictividad social y frenar el avance del comunismo en el viejo continente. Pero su adopción en España suponía además la renuncia por parte del régimen de todo un orden del discurso que, ya desde la Guerra Civil, bendecía las jerarquías naturales impuestas por Dios en la Tierra y las diferencias sustanciales entre aquellos que debian gobernar y aquellos que debían ser gobernados -sin importar claro está las preferencias de estos últimos. Por otro lado, claro está, el keynesianismo extendido por Europa también había calado en determinadas esferas del aparato franquista, cada vez menos capaz de acallar las discrepancias internas.

Junto a esto, y en segundo lugar, dicho sistema de seguridad social permitió la extensión, en una buena parte de la sociedad española, de una determinada política del cuerpo - propia como antes apuntamos de la medicina social del Welfare Statecompletamente ajena a la moral corporal del catolicismo, una moral de la renuncia y del sufrimiento que en muchos sentidos había constituido el eje central de la ética franquista -si se me permite la expresión-, ineficaz ahora ante la llegada del proceso de medicalización contemporáneo y las nuevas imágenes del sí mismo. El cuerpo pasó entonces a ser entendido como un objeto de gobierno por el propio usuario de los servicios médicos, obligados a asegurar por todos los medios posibles la salud del sujeto, imaginado como formando parte de esa red de dependencias mutuas propia de la Biopolítica social del Estado del Bienestar-autoritario, en este caso, y sin derechos políticos, claro está.

La gubernamentalidad del primer franquismo, a través de sus dispositivos biopolíticos idiosincrásicos, fue sin duda capaz de extender por todo el cuerpo social unas determinadas formas de subjetivación que conformaron aquel sujeto característico de la España del período, aquel homo patiens sobre el que se cimentó la dictadura. El aumento de la conflictividad social, la propia confianza de las autoridades franquistas en la fortaleza de su orden político, las discrepancias internas del propio aparato y la creciente presión internacional persuadieron al régimen para que abriera sus fronteras y renunciara a ciertos elementos esenciales de su forma de gobierno. Lo que todo ello supuso fue, a tenor de los visto hasta aquí, la conformación de un cierto tipo de gubernamentalidad autoritaria en la que se conjugaron dispositivos neocapitalistas en el terreno económico, mecanismos propios de la Biopolítica social del Welfare State en el ámbito médico-social, un orden ideológico completamente ajeno a la realidad social, y todo ello en el marco de un sistema estatal dictatorial en el que las libertades políticas y sociales eran absolutamente negadas, y donde cualquier signo de disidencia era atajado con la más brutal represión policial.

Todas estas contradicciones de la nueva forma de gobierno ensayada durante el franquismo desarrollista explican -en nuestra opinión- su ineficacia para generar formas de subjetivación efectivas en una porción mayoritaria de la sociedad española. En el tardofranquismo el régimen fue incapaz de crear formas de conducción 
de conductas adecuadas para asegurar su mantenimiento, y además se vio obligado a admitir resignadamente la extensión por todo el cuerpo social -y dentro del propio sistema- de toda una serie de nuevas actitudes que, con la muerte del dictador, iban a permitir -al menos en parte- la instauración de la democracia. Por supuesto, ciertas notas características de aquella subjetividad del homo patiens propia del primer franquismo pueden detectarse en una buena porción de la sociedad española, aún ciertamente muy desmovilizada y apolitizada, con una cultura democrática palpablemente pobre. Estudios posteriores, seguramente con metodologías distintas, podrán revelar si todo esto fue consecuencia de ciertas políticas del régimen franquista, o si se trata simplemente de un efecto de la sociedad de consumo y de la nueva ideología neoliberal -como parece suceder de hecho en tantas otras partes del Globo. Estamos persuadidos no obstante de que el franquismo extendió ciertas actitudes y comportamientos, ciertas formas de ser y pensar mucho más allá de 1975, notas que perduran aún hoy en una buena fracción de la sociedad española.

\section{Referencias bibliográficas}

Aguilar Fernández, P. (1996): Memoria y olvido de la Guerra Civil Española, Madrid, Alianza.

Alberti LóPez, L. (1985): "La asistencia sanitaria en el conjunto de la previsión social española", en V.V.A.A., 4 Siglos de Acción Social en España. De la Beneficencia al Bienestar Social. Seminario de Historia de la Acción Social, Madrid, Siglo XXI.

Althusser, L. (1974): Escritos, Barcelona, Laia.

APARICIO, M. (1980): El sindicalismo Vertical y la formación del Estado franquista, Barcelona, Eunibar.

Benjamin, W. (1973): Discursos interrumpidos I, Madrid, Taurus.

Boltanski, L. y Chiapello, E. (2002): El nuevo espiritu del capitalismo, Madrid, Akal.

Bustamante, E. (2006): Radio y televisión en España. Historia de una asignatura pendiente de la democracia, Barcelona, Gedisa.

CAmpillo, A. (2001): Variaciones de la vida humana. Una teoría de la historia, Madrid, Akal.

CARreras, A. y TAFunell, X. (2003): Historia económica de la España contemporánea, Barcelona, Crítica.

Casanova, J.; Moreno Gómez, F.; Espinosa, F. y Mir, C. (2002): Matar, morir, sobrevivir: la violencia en la dictadura de Franco, Barcelona, Crítica.

CAstilla Del Pino, C. (1977): "La psiquiatría española (1939-1975)”, en V.V.A.A., La cultura bajo el franquismo, Barcelona, Anagrama, pp. 79-102. 
CAYuela, S. (2009): "El nacimiento de la biopolítica franquista. La invención del «homo patiens»", en Isegoría. Revista de Filosofía Moral y Política, N. ${ }^{\circ} 40$, enero-junio, 2009, pp. 273-288.

CAyuela, S. (2008a): “¿Biopolítica o tanatopolítica? Una defensa de la discontinuidad histórica", en Daimon. Revista Internacional de Filosofía, N. ${ }^{\circ} 43$, pp. 3349.

Cayuela, S. (2008b): "De Auschwitz al Estado del Bienestar. Una aproximación biopolítica a la creación de la identidad europea", en RIPS. Revista de Investigaciones Políticas y Sociológicas, Vol. 7, N. ${ }^{\circ}$ 2, pp. 107-118.

Cenarro, A. (1998): "Muerte y subordinación en la España franquista: el imperio de la violencia como base del «Nuevo Estado»", en Historia Social, N. ${ }^{\circ} 30$, pp. $5-22$.

Cipolla, C. M. (ed.) (1980): Historia económica de Europa, Vol. 6, Economías contemporáneas, Barcelona, Ariel.

DíAz, L. (1997): La radio en España 1923-1997, Madrid, Alianza.

ESPING-ANDERSEN, S. (1993): Los tres mundos del Estado del Bienestar, Valencia, Alfons el Magnànim.

ESPING-ANDERSEN, S. (2000): Fundamentos sociales de las economías postindustriales, Barcelona, Ariel.

Foucault, M. (2005): Vigilar y castigar. Nacimiento de la prisión, Madrid, Siglo XXI.

Foucault, M. (1987): “Le pouvoir, comment s'exerce-t-il?", en Dreyfus, H. y Rabinow, P., Michel Foucault. Un parcours philosophique, Paris, Gallimard, pp. 308-321.

Foucault, M. (2002): “Crisis de la medicina o crisis de la antimedicina?”, en Foucault, M., Estrategias de poder. Obras esenciales II, Barcelona, Paidós.

Foucault, M. (2004): Naissance de la biopolitique. Cours au Collège de France. 1978-1979, Paris, Gallimard/Seuil.

Foucault, M. (1997): «Il faut défendre la société». Cours au Collège de France, 1976, Paris, Gallimard/Seuil, 1997.

Foucault, M. (2004): Sécurité, territoire, population. Cours au Collège de France 1977-1978, Paris, Gallimard/Seuil.

Foucault, M. (2005b): Historia de la sexualidad I. La voluntad de saber, Madrid, Siglo XXI, 2005.

García Capilla, D. (2007): El nacimiento de la bioética, Madrid, Biblioteca Nueva.

Gómez Redondo, R. (1992): La mortalidad infantil española en el siglo XX, Madrid, Siglo XXI-CIS.

GonZÁlez Duro, E. (1978): Psiquiatría y sociedad autoritaria: España 1939-1975, Madrid, Akal. 
GonzÁlez, M. J. (1999): La economía política del franquismo (1940-1970). Dirigismo, mercado y planificación, Madrid, Tecnos.

LABISCH, A. (1985): "Doctors, Workers and the Scientific Cosmology of the Industrial World: The Social Construction of 'Health' and the 'Homo Hygienicus", en Journal of Contemporary History, Vol. 20, N. ' 4, pp. 599-615. LóPez IBOR, J. J. (1964): Los rasgos neuróticos del mundo contemporáneo, Madrid, Cultura Hispánica.

Ludevid, M. (1976): Cuarenta años de Sindicalismo Vertical. Aproximación a la Organización Sindical Española, Barcelona, Laia.

Maquiavelo, N. (1999): El príncipe, Barcelona, Óptima.

MARX, K. (1976): El Capital: crítica de la economía política, Libro I, Madrid, Akal. Miguez, A.; De Miguel, A.; Jiménez Blanco, J.; Castilla del Pino, C.; VázQuez Montalbán, M.; Aguirre, J.; Chamorro, E. y Fernández Alba, A. (1969): España: ¿una sociedad de consumo?, Madrid, Guadiana.

Molinero, C. e Ysàs, P. (1998): Productores disciplinados y minorías subversivas. Clase obrera y conflictividad en la España franquista, Madrid, Siglo XXI.

MuÑoz Machado, S. (1975): La sanidad pública en España. Evolución histórica y situación actual, Madrid, Instituto de Estudios Administrativos.

NaVArRo SANDALINAS, R. (1990): La enseñanza primaria durante el franquismo (1939-1975), Barcelona, PPU.

Nietztsche, F. (1994): La genealogía de la moral, Madrid, Alianza.

Oporto del Olmo, A. (1992): Emigración y ahorro en España, 1959-1986, Madrid, Ministerio de Trabajo y Seguridad Social.

PAlacio, M. (2005): Historia de la televisión en España, Barcelona, Gedisa.

Parra Celaya, M. (2001): Juventudes de Vida Española. El Frente de Juventudes, historia de un proyecto pedagógico, Madrid, Fundación Editorial San Fernando.

Pellejero, C. (ed.) (1999): Historia de la economía del turismo en España, Madrid, Cívitas.

Preston, P. (2001): El holocausto español. Odio y exterminio en la Guerra Civil y después, Barcelona, Debate.

Puelles Benítez, M. (1999): Educación e ideología en la España contemporánea, Madrid, Tecnos.

REHER, D. (2003): "Perfiles demográficos de España, 1940-1960”, en Barciela, C. (ed.): Autarquía y mercado negro. El fracaso económico del primer franquismo, 1939-1959, Barcelona, Crítica, pp. 11-26

Richards, M. (1999): Un tiempo de silencio. La Guerra Civil y la cultura de la represión en la España de Franco, 1936-1945, Barcelona, Crítica, 1999.

Richmond, K. (2004): Las mujeres en el fascismo español. La Sección Femenina de Falange, 1934-1959, Madrid, Alianza. 
RodRÍGUEZ OCAÑA, E. (1999): "La construcción de la salud infantil. Ciencia, medicina y educación en la transición sanitaria en España", en Historia Contemporánea, N. ${ }^{\circ} 18$, pp. 19-42.

Ruiz Carnicer, M. A. y Gracia García, J. (2001): La España de Franco (19391975). Cultura y vida cotidiana, Madrid, Síntesis.

SÁez Marín, J. (1988): El Frente de Juventudes. Política de Juventud en la España de la Posguerra (1937-1960), Madrid, Siglo XXI.

SÁNCHEZ LÓPEZ, R. (1990): Mujer española, una sombra de destino en lo universal. Trayectoria histórica de Sección Femenina de Falange (1934-1977), Murcia, Universidad de Murcia.

SÁnchez Recio, G. (2002): "El Sindicalismo Vertical como instrumento político y económico del Régimen franquista", en Pasado y memoria. Revista de Historia Contemporánea, N. ${ }^{\circ}$ 1, pp. 5-37.

SENNETT, R. (2001): La corrosión del carácter. Las consecuencias personales del trabajo en el nuevo capitalismo, Barcelona, Anagrama.

SERRANo SAnZ, J. Ma . y PARDos, E. (2002): "Los años de crecimiento del franquismo", en Comín, F.; Hernández, M. y Llopis, X. (eds.): Historia económica de España, Siglos X-XX, Barcelona, Crítica, pp. 369-395.

VÁzQUez GARCíA, F. (2009): La invención del racismo. Nacimiento de la biopolitica en España, 1600-1940, Madrid, Akal.

VegarA, J. Mª (1971): La organización científica del trabajo, ¿ciencia o ideología?, Barcelona, Fontanella.

VV. AA. (1962): Informe del Banco internacional de reconstrucción y fomento: El desarrollo económico en España, Madrid, Oficina de Coordinación y Programación Económica.

Salvador Cayuela Sánchez

Departamento de Filosofía

Universidad de Murcia

scayuela@um.es 